\title{
७MONÇÕES

\section{Na contramão do unilateralismo: assistência alimentar internacional dos Estados Unidos no governo Trump}

\section{Against unilateralism: United States international food assistance in the Trump government}

Contra el unilateralismo: asistencia alimentaria internacional de Estados

\section{Unidos bajo la administración Trump}

\begin{abstract}
Atos Dias
Doutorando em Ciência Política na Universidade Federal de Pernambuco (UFPE). Membro do Grupo de Pesquisa sobre Fome e Relações Internacionais (FomeRI)

Recife, Pernambuco, Brasil

E-mail: atosrabi@gmail.com

Orcid: https://orcid.org/0000-0001-9690-5696
\end{abstract}

Thiago Lima

Professor do Departamento de Relações Internacionais, Universidade Federal da Paraíba (UFPB).

Coordenador do Grupo de Pesquisa sobre Fome e Relações Internacionais (FomeRI). João Pessoa, Paraíba, Brasil

E-mail: tlima@ccsa.ufpb.br

Orcid: https://orcid.org/0000-0001-9183-3400

Resumo: Os Estados Unidos têm se caracterizado como o principal doador de assistência alimentar para o mundo desde a década de 1950, quando programas de doação internacional de alimentos foram criados. Ao chegar à Casa Branca, Donald Trump propôs extinguir os programas de assistência alimentar internacional, como parte de sua agenda de política externa de desengajamento das organizações internacionais e do multilateralismo. Apesar disso, o que se percebeu de seu governo foi uma continuidade deste tipo de ajuda externa. Quais fatores contribuíram para a continuidade da assistência alimentar internacional dos Estados Unidos? 
A partir de uma análise de política externa do governo Trump, o artigo aponta para três principais razões: (a) a posição contrária de congressistas e membros do governo aos cortes em ajuda externa propostos pelos "falcões do orçamento" do governo Trump; (b) a escolha estratégica do republicano David Beasley como diretor geral do Programa Mundial de Alimentos; e o (c) lobby feito pelo triângulo de ferro (produtores e processadores agrícolas, empresas de transporte marítimo e ONGs de distribuição). $\mathrm{O}$ artigo contribui para entender a influência que atores para além do chefe de Estado, e mediados por instituições (nacionais ou internacionais), podem ter na política externa estadunidense.

Palavras-chave: Assistência Alimentar Internacional; Estados Unidos; Donald Trump.

Abstract: Historically, the United States is the world's largest food donor. But upon reaching the White House, Donald Trump proposed to extinguish international food assistance programs as part of his foreign policy agenda of disengagement from international organizations and multilateralism. Despite this, what was perceived of his government was a continuation of this type of foreign aid. What factors contributed to the continuity of the United States' international food assistance? From an analysis of the Trump administration's foreign policy, the article points to three main reasons: (a) the contrary position of congressmen and members of the government to the foreign aid cuts proposed by the Trump administration's 'budget hawks'; (b) the strategic choice of Republican David Beasley as director-general of the World Food Program; and (c) lobbying by the iron triangle (agricultural producers and processors, shipping companies and distribution NGOs). The article helps to understand the influence that actors other than the head of state, and mediated by institutions (national or international), can have on American foreign policy.

Keywords: International Food Assistance; United States; Donald Trump.

Resumen: Históricamente, Estados Unidos es el mayor donante de alimentos del mundo. Pero al llegar a la Casa Blanca, Donald Trump propuso poner fin a los programas internacionales de asistencia alimentaria como parte de su agenda de política exterior de desvinculación de las organizaciones internacionales y el multilateralismo. Pese a ello, lo que se percibió de su gobierno fue una continuación de este tipo de ayuda exterior. ¿Qué factores contribuyeron a la continuidad de la asistencia alimentaria internacional de Estados Unidos? A partir de un análisis de la política exterior de la administración Trump, el artículo apunta a tres razones principales: (a) la oposición de congresistas y miembros del gobierno a los recortes en la ayuda exterior propuestos por los "halcones del presupuesto" de la administración Trump; (b) la elección estratégica del republicano David Beasley como director general del Programa Mundial de Alimentos; y (c) cabildeo por parte del triángulo de hierro (productores y procesadores agrícolas, compañías navieras y ONG de distribución). EI artículo contribuye a comprender la influencia que los actores más allá del jefe de Estado, y mediados por instituciones (nacionales o internacionales), pueden tener en la política exterior de Estados Unidos.

Palabras clave: Asistencia Alimentaria Internacional; Estados Unidos; Donald Trump.

Recebido em

13/07/2020.

Aceito em

24/08/2021. 


\section{INTRODUÇÃO ${ }^{1}$}

Os Estados Unidos têm historicamente utilizado seus programas de assistência alimentar internacional como ferramenta de política externa ligada a interesses econômicos, políticos e de segurança nacional (PORTILLO, 1987). Na década de 1950, o programa denominado Public Law (PL) 480 (mais tarde renomeado para Food for Peace) - primeiro e mais importante instrumento estadunidense de assistência alimentar internacional - foi criado pelo presidente Dwight D. Eisenhower visando, segundo suas próprias palavras, "lay the basis for a permanent expansion of our exports of agricultural products with lasting benefits to ourselves and people of other lands" (EISENHOWER, 1955). Embora tenha passado por reformas durante seus anos de existência - principalmente no intuito de aproximá-la a fins mais humanitários, tornando-a mais efetiva e menos custosa - os objetivos acima citados parecem continuar influenciando fortemente a política de assistência alimentar internacional estadunidense. De um modo ou de outro, o fato é que os Estados Unidos são, desde o pósSegunda Guerra Mundial, indiscutivelmente o maior doador mundial de alimentos (CLAPP, 2012)

A chegada de Donald Trump ao poder em 2017 parecia trazer mudanças nesse cenário. No contexto de sua proposta de desengajamento das obrigações internacionais e do enfraquecimento das organizações internacionais, a expectativa era de que os programas de assistência alimentar internacional fossem reduzidos ou extintos (QUINN, 2016).

Essa perspectiva soava demasiadamente preocupante para o Programa Mundial de Alimentos (PMA) da Organização das Nações Unidas (ONU) e para agentes humanitários. Apesar de questionada quanto aos seus métodos, é inegável a importância das doações de alimentos dos Estados Unidos e qualquer corte mais agudo certamente prejudicaria os esforços de amenizar as catástrofes humanitárias justamente no período em que há a maior quantidade de refugiados já computada na História, já antes da pandemia de Covid-19.

\footnotetext{
${ }^{1}$ O presente trabalho foi realizado com apoio da Coordenação de Aperfeiçoamento de Pessoal de Nível Superior - Brasil (CAPES) - Código de Financiamento 001.
} 
Apesar das ameaças de corte, no entanto, o que se observou dos dados da assistência alimentar internacional dos EUA foi, de modo geral, um aumento e continuidade. No caso das doações ao PMA, houve um crescimento recorde de doações estadunidenses para o ano de 2020 (de acordo com os dados disponíveis do PMA) (WFP, 2021). Por que a gestão Trump não diminuiu ou mesmo extinguiu os gastos com as políticas de assistência alimentar internacional dos EUA?

O objetivo do artigo é examinar o porquê, nesse campo específico, o governo Trump contrariou sua política externa de desengajamento e de enfraquecimento do multilateralismo. Buscamos explicar - a partir da análise de dados das doações, de relatórios oficiais, de audiências do Congresso e de artigos na mídia - quais fatores contribuíram para o crescimento e continuidade da assistência alimentar internacional estadunidense.

Esse é, portanto, um estudo de caso ancorado no campo da Análise de Política Externa (APE), cujo objetivo é compreender ações de política externa que pareçam irracionais ou incoerentes. Especificamente, abordamos o caso a partir de uma perspectiva pluralista da APE que busca analisar as relações entre atores relevantes, mediados por instituições (MILNER, 1997). Quer dizer, recusa-se atribuir ao chefe de Estado todos os elementos necessários para a compreensão do fenômeno em tela. Desse modo, identificar interesses, as relações de poder entre os atores e o papel das instituições são ações fundamentais. No caso específico dos Estados Unidos, apoiamo-nos também no quadro analítico desenvolvido por Vigevani, Mendonça e Lima (2018). Para os autores, as pressões isolacionistas e protecionistas estão sempre presentes nos debates referentes à formulação de política econômica internacional dos EUA, mas tendem a ser contrabalançadas por grupos de interesses, atores políticos e também limitadas por instituições, ora no Executivo, ora no Legislativo. Como observamos, esse parece ter sido justamente o caso na política de assistência alimentar internacional.

O artigo está organizado em quatro partes. Após essa introdução, na seção dois apresentamos elementos gerais da política externa de Trump. A seção três indica os motivos para a continuidade e crescimento da assistência alimentar internacional no governo Trump à luz da imagem do 'triângulo de ferro' (DIVEN, 2006; CLAPP, 2012; LIMA; DIAS, 2016). A seção quatro oferece considerações finais. 


\section{ELEMENTOS GERAIS DA POLÍTICA EXTERNA DE TRUMP}

O programa de assistência alimentar internacional dos EUA foi o primeiro do tipo na História. Até então, ajudas ocorriam de forma pontual, mas um programa de alcance global foi pela primeira vez organizado com a PL 480, após a II Guerra Mundial. Esse programa foi duramente criticado ao longo do tempo, pois estava claro que parte fundamental de seu objetivo era promover interesses econômicos e de política externa dos Estados Unidos. A partir dos anos 1970, com a profissionalização da cooperação internacional, inclusive da ajuda humanitária, surgiram questionamentos também em termos da efetividade dos métodos e da eficiência da gestão da ajuda². Em resposta a essas críticas, houve tentativas de reformar os instrumentos e métodos da assistência alimentar internacional dos Estados Unidos, por parte de presidentes Republicanos e Democratas, como George W. Bush e Barack Obama, mas essas avançaram timidamente em comparação com outros grandes doadores (como União Europeia e Canadá), principalmente pela resistência encontrada no Congresso (CLAPP, 2012; LIMA; DIAS, 2016).

O governo Trump foi iniciado com outra perspectiva. Sua prioridade inicial era promover cortes nas diversas modalidades de assistência humanitária oferecida pelo país. Essa tarefa - que é avessa ao histórico de protagonismo de Washington na distribuição internacional de comida e de fomento ao PMA - se coadunava à agenda de política externa prometida em sua campanha e, aplicada na prática, destoava da tradição estadunidense de encabeçar a manutenção de uma ordem internacional liberal por meio do multilateralismo, ainda que recorrendo a políticas unilaterais e protecionistas simultaneamente (VIGEVANI; MENDONÇA; LIMA, 2018).

De fato, a eleição de Trump representou um perigo à sustentação da ordem internacional vigente. Como explica Stokes (2018), o governo Trump encorajou de forma ativa o desmantelamento da União Europeia, sobretudo a saída do Reino Unido por meio do Brexit;

\footnotetext{
2 Devido a esses questionamentos, que atingiram também outros prestadores de cooperação e doadores internacionais da Organização para a Cooperação e Desenvolvimento Econômico (OCDE), os maiores doadores de alimentos do mundo reformaram seus programas de ajuda. Destaque para a desvinculação (untying) da ajuda alimentar (CLAPP, 2012).
} 
questionou a participação dos EUA na Organização do Tratado do Atlântico Norte (OTAN), bem como o papel da instituição para a segurança internacional; e deu maior ênfase a um nacionalismo econômico ao realizar forte crítica à globalização. Stokes (2018) vai mais além ao dizer que, se com o fim da Guerra Fria o paradigma cultural dominante foi o "fim da história" - como assim apregoou Fukuyama (1992) - a vitória de Trump pareceu representar um impasse à preponderância de um internacionalismo liberal ao acentuar a primazia do Estado-nação estadunidense a partir da (nem tão nova) política externa denominada "America First", que foi adotada em alguns momentos da história dos EUA e que tinha como dois principais pilares o nacionalismo e o unilateralismo/bilateralismo.

É importante salientar que boa parte da retórica de campanha se tornou efetivamente política externa. Duas horas depois de ter assumido a presidência, Trump enviou um comunicado oficial afirmando que pretendia renegociar o Acordo de Livre Comércio da América do Norte (Nafta, sigla em inglês), o que culminou no Acordo Estados Unidos-MéxicoCanadá (USMCA, sigla em inglês) (MARIANO; MATTOS; SUGAHARA, 2019). Três dias após ter assumido a presidência, a Casa Branca também assinou um memorando presidencial para retirar os EUA da Parceria Transpacífica (TPP, sigla em inglês) (MENEZES; CARVALHO; LEITE, 2021). No campo do comércio internacional, pela primeira vez a presidência era ocupada por um mandatário que não defendia o livre-comércio como um princípio (MENDONÇA et al, 2019).

De acordo com Poggio (2018), o governo Trump representava uma espécie de pensamento paleoconservador no que diz respeito à política externa. No contexto dos Estados Unidos, o movimento articulado de intelectuais conservadores começou a ser desenhado durante a década de 1950 e se consolidou na década posterior. Poggio (2018) explica que esse movimento teve como principal "pedreiro" William Buckley Jr. que, ao criar a revista intitulada National Review em 1955, intuiu abrigar diversas vertentes do conservadorismo (principalmente libertários e tradicionalistas) em um periódico que permitisse um diálogo entre diferentes vertentes conservadoras e, mais do que isso, fosse capaz de promovê-las dentro da sociedade estadunidense. O "cimento" que permitiu esse alinhamento dialógico entre diferentes vertentes de pensamentos conservadores foi justamente o anticomunismo dos EUA em meio à Guerra Fria. 
Com a derrocada da União Soviética e o consequente fim da Guerra Fria, no entanto, abriu-se espaço para a cisma entre o movimento conservador até então unificado em sua base ideológica. A fragmentação, contudo, teria começado ainda a partir da metade da década de 1980, entre os neoconservadores (de posição mais liberal) e os paleoconservadores (um grupo mais ligado aos tradicionalistas). Apesar do prefixo "paleo" na palavra "paleoconservadorismo" dar uma ideia de que essa corrente seja mais antiga dentre as tendências conservadoras, ambas aqui tratadas (paleo e neo) surgiram na mesma época como um efeito da divisão no movimento conservador estadunidense (WOLTERMANN, 1993). Enquanto os neoconservadores se destacam por uma postura mais secularista, os paleoconservadores defendem a estreita relação entre cristianismo e conservadorismo.

De forma mais específica, em termos de política externa, os neoconservadores advogam uma ação internacional ativa (ou intervencionista), moldada principalmente pela promoção da democracia e do comércio internacional. A abordagem dos neoconservadores à política externa segue a lógica da agenda doméstica que essa corrente defende. Isso significa a promoção do estilo ocidental contemporâneo da democracia representativa, juntamente com uma cultura cívica com base nos direitos humanos e na igualdade. $\mathrm{O}$ argumento apresentado pelo neoconservadorismo é de que: se esse tipo de agenda é bom para estadunidenses e europeus ocidentais, deve ser igualmente bom para o resto do mundo (WOLTERMANN, 1993).

Em contraposição, os paleoconservadores possuem uma perspectiva mais isolacionista, baseada no nacionalismo, no protecionismo econômico, no combate ao multiculturalismo e numa posição antimigratória (WOLTERMANN, 1993). Para Pat Buchanan, um dos principais protagonistas do paleoconservadorismo nos anos 1990, os EUA devem ser uma república constitucional e não um império. Segundo Buchanan, as repúblicas cuidam dos seus assuntos próprios, seus governos possuem poderes limitados e seu povo está muito preocupado com seu próprio país, o que não dá espaço para que se atentem a problemas em outros países (FRANCIS, 2002).

Os paleoconservadores possuíam pouca expressividade dentro das instituições políticas e na sociedade civil, de um modo geral. Essa realidade, no entanto, teria mudado com a eleição de Donald Trump. 
Poggio (2018) aponta três fatores que contribuíram para a derrota do neoconservadorismo enquanto vertente dominante do movimento conservador: o fracasso da guerra do Iraque, a crise financeira de 2008 e a eleição de Barack Obama (ver PECEQUILO, 2017). A desconfiança que envolveu o neoconservadorismo abriu espaço para o fortalecimento das ideias paleoconservadoras, nas quais Trump pareceu basear sua agenda de política externa: desde o slogan "America First", que foi bastante utilizado por Pat Buchanan, até a renúncia da liderança da ordem liberal internacional, incluída aí uma política menos intervencionista no exterior. É dentro dessa perspectiva que se propunham cortes na ajuda humanitária internacional e, de modo mais específico, na assistência alimentar oferecida pelos EUA ao mundo.

Embora tenha falado de maneira reduzida sobre o tema da ajuda internacional durante a campanha presidencial, pouco depois de eleito Donald Trump declarou que o governo pararia de enviar ajuda a países que "odeiam" os EUA; e que iria redirecionar para o território nacional a ajuda humanitária dada ao estrangeiro. Antes mesmo de Trump assumir, especialistas como Alex Thier - ex-funcionário da Agência dos Estados Unidos para o Desenvolvimento Internacional (USAID, sigla em inglês) - especularam que existia chance real de que a USAID (principal agência de ajuda humanitária dos EUA e do mundo) poderia ser abolida ou diminuída e incorporada pelo Departamento de Estado (QUINN, 2016).

Uma vez na presidência, Trump emitiu sua National Security Strategy. Esse é um documento sempre importante, pois dá o tom do vínculo entre os diversos temas com a questão da segurança. Nele, o governo de Trump assim se referia à assistência humanitária oferecida pelos EUA ao mundo:

The United States will continue to lead the world in humanitarian assistance. Even as we expect others to share responsibility, the United States will continue to catalyze international responses to man-made and natural disasters and provide our expertise and capabilities to those in need. We will support food security and health programs that save lives and address the root cause of hunger and disease. We will support displaced people close to their homes to help meet their needs until they can safely and voluntarily return home (p. 42).

The United States will partner with governments, civil society, and regional organizations to end long-running, violent conflicts. We will encourage reform, working with promising nations to promote effective governance, improve the rule of law, and develop institutions accountable and responsive to citizens. We

Revista Monções, Dourados, MS, V.10, №19, jan. / jun. 2021, 2316-8323 
will continue to respond to humanitarian needs while also working with committed governments and regional organizations to address the root causes of human suffering. If necessary, we are prepared to sanction government officials and institutions that prey on their citizens and commit atrocities. When there is no alternative, we will suspend aid rather than see it exploited by corrupt elites (p. 52) (WHITE HOUSE, 2017, p. 42, 52).

Entretanto, em um discurso em janeiro de 2018, numa mostra de Realismo explícito, Trump afirmou que o governo planejava vincular a ajuda externa ao apoio à política externa estadunidense. É claro que isso é corriqueiro nas relações internacionais, mas assumir esse discurso demonstra que não há pudores ao afrontar o multilateralismo e, mais especificamente, o regime multilateral de ajuda humanitária.

Quanto à operacionalização da política de assistência alimentar internacional, Trump deixou claro o interesse em cortar alguns programas desse tipo, sobretudo três: McGovernDole Food for Education, Food for Peace (PL 480) e Food for Progress. Importante salientar que essas três modalidades trabalham com entrega direta de alimentos de origem estadunidense a países e organizações internacionais, principalmente o PMA. Para a proposta de orçamento do ano de 2018, o governo Trump objetivou cortar as duas primeiras modalidades anteriormente citadas. Esse corte representaria uma economia de US\$ 2 bilhões, cerca de 7\% do total da ajuda externa oferecida pelos EUA. De acordo com o governo Trump, não existiriam evidências de que ambas as modalidades pudessem ser efetivamente implementadas pois, na verdade, elas se mostravam ineficazes, lentas e de alto custo (WERFT, 2017). Propostas de reestruturação por meio de enxugamento também foram apresentadas para os orçamentos de 2019 e de $2020^{3}$, destacando que o então modelo de ajuda seria ineficiente.

Como resposta, grupos de lobistas e políticos tiveram sucesso em impedir o plano de reforma de Trump ${ }^{4}$. Temos aqui uma amostra dos freios e contrapesos do sistema político

\footnotetext{
3 Para o Ano Fiscal de 2020 - pela terceira vez consecutiva - Trump propôs cortar os fundos McGovern-Dole Food for Education e o Título II do Food for Peace (que dispõe de doação direta de alimentos a países estrangeiros). A diferença para o ano de 2020 é que a proposta previa a extinção desses fundos independentes e a incorporação de ambos em demais contas de assistência humanitária. O Congresso, no entanto, não adotou as propostas apresentadas pelo governo (CASEY; MORGENSTERN, 2020).

${ }^{4}$ Note que críticas semelhantes a esses programas também foram feitas pelas presidências de Obama e Bush filho, e que as reformas propostas pelo Executivo também foram restringidas (LIMA; DIAS, 2016).
} 
estadunidense, ou do papel dos diques institucionais em conter uma guinada antiliberal e antimultilateral nos EUA. Isso não significa, no entanto, que nenhuma reforma tenha sido feita, ainda que por vias indiretas ${ }^{5}$.

Observando o gráfico 1, os dados mostram que a assistência alimentar internacional fornecida pelos EUA parece se opor à proposta de política externa de Trump de diminuir os programas. Houve aumento do valor desembolsado em 2017 e 2018. E mesmo com a queda do valor desembolsado em 2019 , os gastos permaneceram em um patamar alto se comparado a governos anteriores dentro da série histórica, demonstrando, portanto, uma continuidade desse tipo de política durante a gestão de Trump.

Analisando os resultados de 2017 , constata-se um aumento de $29,9 \%$ em relação à média da série histórica. Em 2018, houve um aumento de 47,6\% em relação à média. 0 resultado de 2019 representou uma queda em valores absolutos em relação aos dois anos anteriores, mas ainda assim 33,3\% maior do que a média da série histórica. De modo geral, os valores desembolsados pela gestão Trump são os maiores da série histórica, que incluem as gestões de George W. Bush e Barack Obama.

Gráfico 1 - Obrigações e gastos dos EUA com assistência alimentar internacional ${ }^{6}$

\footnotetext{
${ }^{5} \mathrm{Na}$ parte 3 do artigo, citamos em detalhes a reforma feita por meio da Farm Bill de 2018 que extinguiu a obrigatoriedade da prática de monetização.

${ }^{6}$ Os dados foram conformados levando-se em consideração o somatório, para cada ano fiscal, das atividades de ajuda externa dos seguintes fundos de financiamento (funding account): Public Law 480 Title I Direct Credit and Food for Progress Program Account; Public Law 480 Title I Food for Progress, Credits Program Account; Public Law 480 Title II Grants; McGovern-Dole International Food for Education and Child Nutrition Program Grants; Commodity Credit Corporation Fund; International Disaster Assistance (especificamente as atividades de assistência alimentar emergencial e não emergencial e alimentação escolar); e atividades de outros fundos com propósito ligado à assistência alimentar emergencial e não emergencial e alimentação escolar. Os valores estão
} 


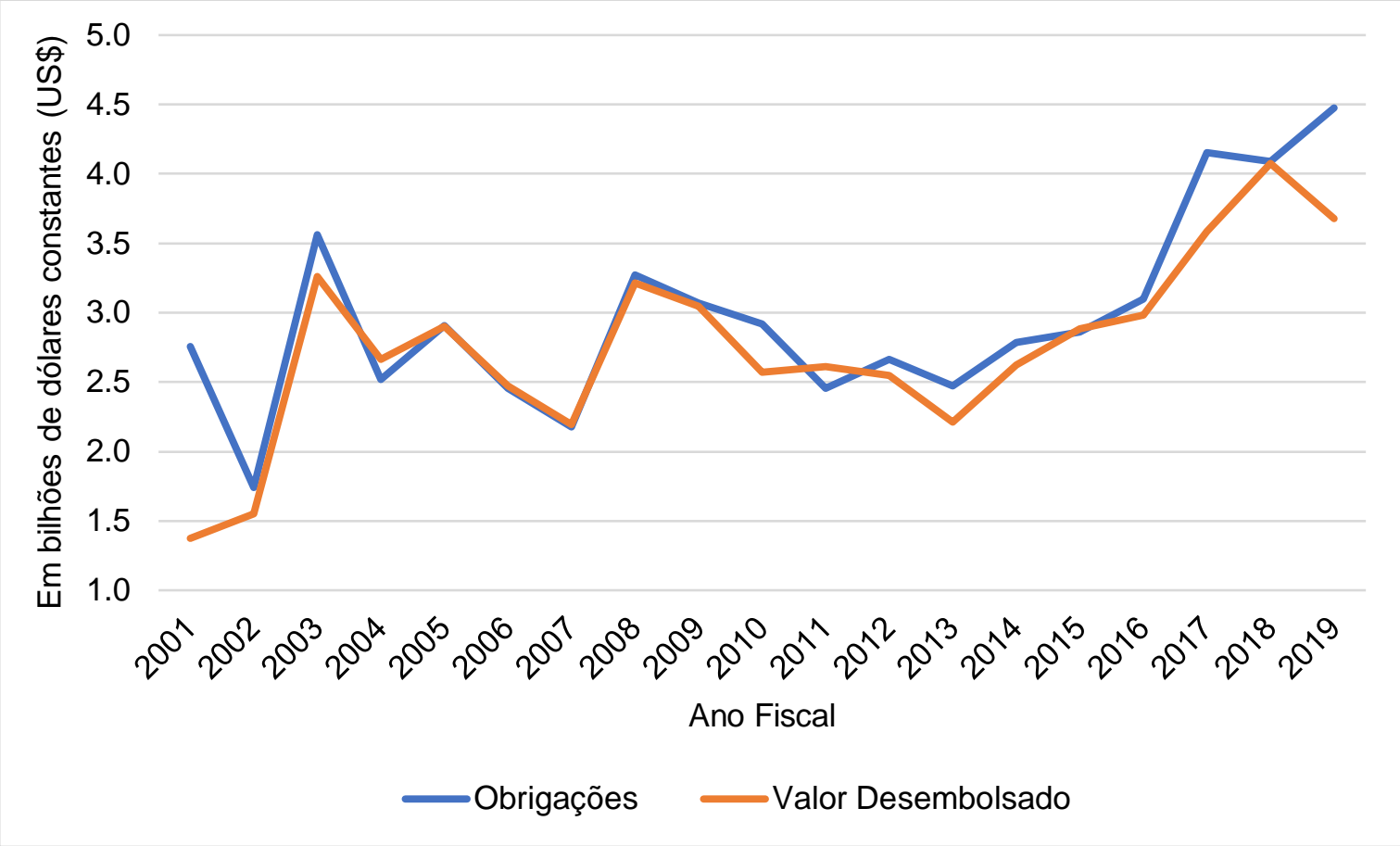

Fonte: Elaboração própria com base em USAID, 2021.

É bastante perceptível que as obrigações e o valor desembolsado se mantiveram altos entre 2017 e 2019, apenas com uma leve queda dos gastos no último ano da série histórica. De modo geral, os dados demonstram que, embora houvesse iniciativa por parte da gestão Trump em desobrigar gastos com assistência alimentar internacional, os cortes não se concretizaram, o que revela uma disputa entre forças políticas antagônicas.

Nossa análise considera que pelo menos três fatores contribuíram para a continuidade e aumento de doações de Washington na forma de assistência alimentar internacional: (a) a posição contrária de congressistas e membros do próprio governo Trump; (b) a escolha estratégica do republicano David Beasley como diretor geral do PMA; e o (c) lobby feito pelo triângulo de ferro (produtores e processadores agrícolas, empresas de transporte marítimo e $\mathrm{ONGs}^{7}$ de distribuição), grupo diretamente interessado pela continuidade dos gastos do governo dos EUA com assistência alimentar internacional. Na seção seguinte analisamos os

ajustados de acordo com a inflação. Os dados referentes ao ano de 2020 não estão conformados e, portanto, não foram incluídos.

${ }^{7}$ Organizações não governamentais. 
três fatores acima citados. Além disso, trataremos da guerra comercial entre EUA e China como um possível fator que também pode ter contribuído para a continuidade da assistência alimentar internacional estadunidense. A queda nas exportações de commodities agrícolas estadunidenses para a China (devido às tarifas impostas por Pequim) pode ter servido de alerta ao governo Trump para a importância estratégica da assistência alimentar internacional como uma ferramenta eficaz no escoamento de excedentes e na garantia de remuneração da produção agrícola nos EUA.

\section{PERMANÊNCIA DA ASSISTÊNCIA ALIMENTAR INTERNACIONAL NO GOVERNO TRUMP: ANALISANDO QUATRO FATORES}

Como explicado anteriormente, entre as propostas do governo Trump estava a realização de cortes profundos na ajuda externa, sobretudo para aqueles países considerados "inimigos" dos EUA. Tendo isso em vista, o governo propôs, em 2017, a diminuição do orçamento básico do Departamento de Estado e da USAID (MORELLO, 2017). No entanto, como apresentado no gráfico 2, de 2017 para 2018 o valor desembolsado foi praticamente igual. E em 2019, houve leve queda, cerca de 5\%, em relação a 2018. Nos três anos, as obrigações caíram seguidamente, embora não se observe nenhuma anormalidade em relação à série histórica.

Gráfico 2 - Gastos dos EUA com ajuda externa por ano ${ }^{8}$

\footnotetext{
${ }^{8}$ Os dados representam o universo da ajuda externa econômica e militar enviada pelos EUA por ano fiscal em valores constantes/reais. Até a conclusão do artigo, os dados referentes ao ano de 2020 não estavam consolidados e, portanto, não foram incluídos.
} 


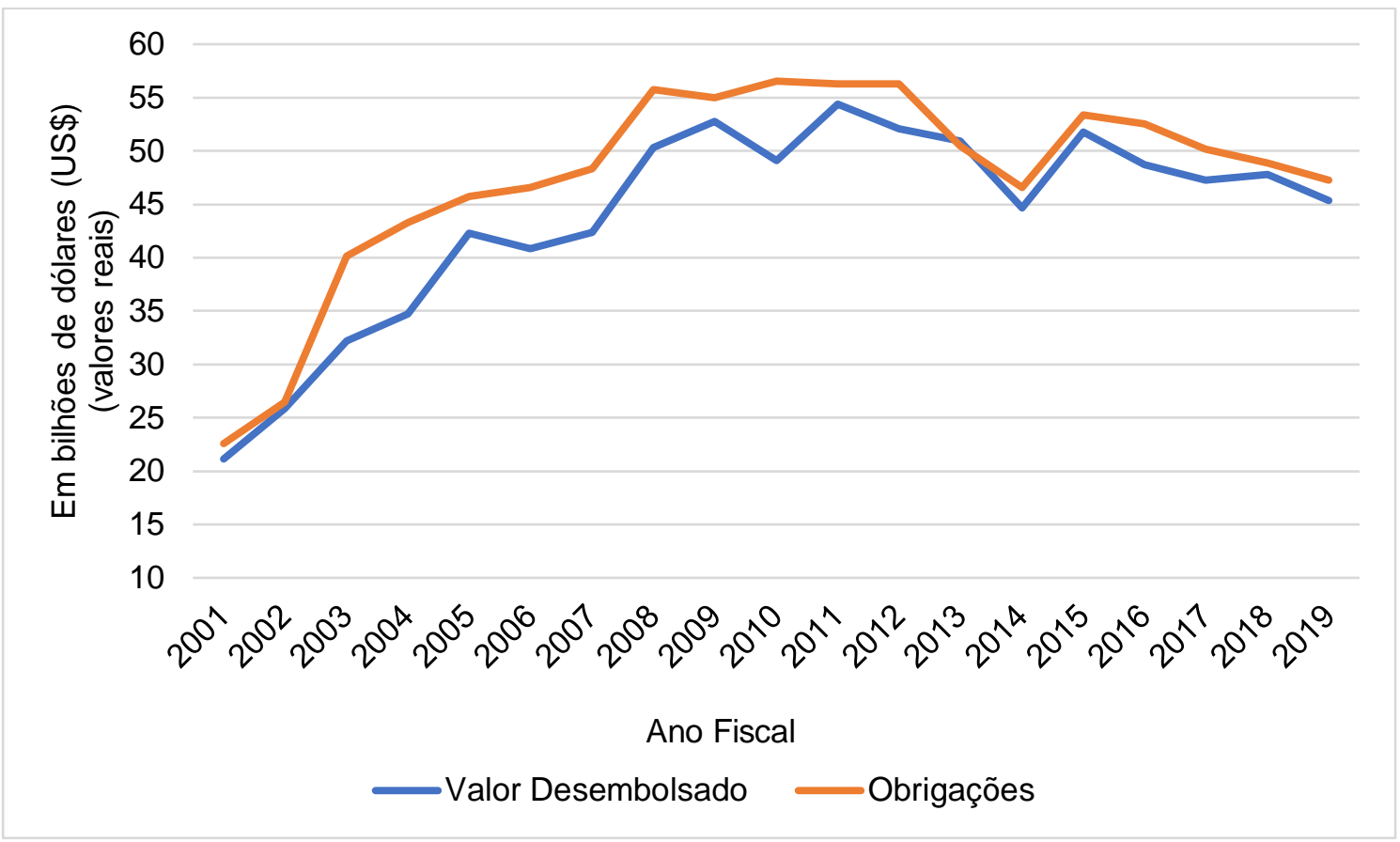

Fonte: Elaboração própria com base em USAID, 2021.

Por que os cortes não foram maiores? Nesse quesito, é necessário levar em consideração o papel de congressistas e membros do próprio governo que trabalharam para que os cortes fossem os mais razoáveis possíveis.

Tanto em 2018 quanto em 2019 - no mês de agosto - Trump foi convencido a recuar de propostas apresentadas pelos chamados "falcões do orçamento" (budget hawks) do governo (dentre eles Mick Mulvaney, que liderava a White House's Office of Management and Budget) que previam corte significativo na parcela do orçamento (cerca de quatro bilhões de dólares) destinada à ajuda estrangeira que já havia sido aprovada pelo Congresso para os respectivos anos. Dentre os que buscaram convencer Trump contra os cortes estavam congressistas (democratas e republicanos), o secretário do Tesouro estadunidense Steven Mnuchin e, sobretudo, o secretário de Estado Mike Pompeo (WONG; KARNI; COCHRANE, 2019; WADHAMS; FABIAN, 2019).

Entre os congressistas contrários às propostas de corte destacou-se Nancy Pelosi (democrata), presidente da Câmara de Deputados dos EUA, inimiga política de Trump e terceira na linha de sucessão à presidência. Na época da proposta de corte orçamentário em ajuda externa apresentada em 2019, Pelosi chegou a afirmar que a ação violava a boa-fé das negociações orçamentárias e que também poderia comprometer o acordo Revista Monções, Dourados, MS, V.10, №19, jan. / jun. 2021, 2316-8323 
orçamentário de dois anos entre os democratas e o governo Trump. Pelosi, à época, chegou a enviar um comunicado a Mnuchin pedindo para que o mesmo trabalhasse junto à Administração no intuito de interromper a proposta. Dentre os republicanos que se posicionaram contra a proposta de cortes estavam o senador Lindsey Graham (Carolina do Sul) e o deputado Hal Rogers (Kentucky); nas palavras de ambos, o possível corte prejudicaria os interesses de segurança nacional e encorajaria os adversários dos EUA (BOYER, 2019). Notase, portanto, que o papel atribuído à ajuda humanitária na política externa dos EUA, conforme descrito na National Security Strategy de 2017, não oferecia segurança a muitos atores políticos.

Não tendo realizado os cortes, o governo Trump empregou uma política externa de 'custo-benefício' para alguns casos: em 2019, revogou a ajuda de US\$ 1,3 bilhão para o Paquistão e de US\$ 500 milhões para a Palestina. Nas palavras do presidente estadunidense: "We giving billions of dollars to countries that don't even like us, and I've been cutting that a lot". Na visão de Trump, usar a ajuda externa como instrumento de barganha seria uma alavanca útil para a diplomacia. Trump ainda afirmou que, no caso do Paquistão, o corte serviu para promover uma relação favorável com Islamabade e um provável futuro acordo com a Palestina (BOYER, 2019; WADHAMS; FABIAN, 2019).

No que se refere à política de assistência alimentar internacional, quando o governo Trump propôs pôr fim a programas do tipo (McGovern-Dole Food for Education e Food for Peace) em 2017, diversos congressistas republicanos e democratas se posicionaram contrários à medida. O republicano Ted Yoho (Flórida) afirmou à época que se a ajuda externa fosse cortada, seria necessário comprar mais munição. Outro congressista republicano, Filemon Vela (Texas), defendeu que o que deveria estar em discussão seria o aprimoramento dos programas de assistência alimentar internacional no lugar do debate sobre os cortes. 0 democrata Jimmy Panetta (Califórnia) argumentou que o corte na assistência alimentar de Washington deixaria um vácuo na liderança internacional que certamente outros países poderiam preencher. E o republicano Mike Conaway (Texas) - então presidente do Comitê de Agricultura da Câmara - declarou que os cortes nos programas de assistência alimentar pareciam contraintuitivos aos ideais do "America First" (WERFT, 2017). Parece-nos, assim, que a pressão exercida por congressistas e membros do próprio governo Trump 
pode ter contribuído para a manutenção dos programas de assistência alimentar internacional dos EUA ${ }^{9}$.

O segundo fator a ser levado em consideração a fim de entendermos, além da continuidade, o crescimento contraintuitivo da assistência alimentar internacional, diz respeito à atuação do Programa Mundial de Alimentos. O PMA é uma agência da ONU, criada na década de 1960, com o intuito de oferecer assistência alimentar internacional ao mundo e tem os EUA como seu principal financiador histórico (CLAPP, 2012).

Em 2017, Trump indicou o ex-governador da Carolina do Sul, o republicano David Beasley, para o cargo de diretor executivo do PMA (o mais alto da instituição). A ONU acatou a indicação no que parece ter sido um movimento para tentar frear os cortes dos recursos estadunidenses para o $\mathrm{PMA}^{10}$. Note-se que os cinco estadunidenses que cronologicamente antecederam Beasley na gestão do PMA possuíam alguma experiência com políticas de assistência alimentar internacional, enquanto o ex-governador não tinha qualquer vivência com o ofício, nem com o sistema ONU. Especialistas da ONU esperavam que, com a nomeação, Beasley pudesse ser capaz de convencer "seus amigos de Washington" a poupar o PMA dos cortes da Casa Branca (LYNCH, 2017; LEIMBACH, 2019; USA SENATE, 2019).

Três cabeças que poderiam influenciar o destino orçamentário dos EUA para o PMA pertenciam à rede de contato do novo diretor executivo da agência: a ex-embaixadora dos EUA na ONU e ex-governadora da Carolina do Sul Nikki Haley; o senador republicano (conterrâneo de Beasley) Lindsey Graham, que presidia o subcomitê State, Foreign Operations, and Related Programs responsável por supervisionar o financiamento estadunidense à ONU; e o chefe do orçamento da Casa Branca à época, Mick Mulvaney (LYNCH, 2017; LEIMBACH, 2019; USA SENATE, 2019).

Desde a nomeação de Beasley em 2017, a contribuição dos EUA para o PMA não apenas se manteve como atingiu um pico em 2020 dentro da série histórica, como se observa

\footnotetext{
${ }^{9}$ Mesmo assim, o governo Trump não desistiu de reformar e diminuir os instrumentos de assistência alimentar internacional, como apontado na nota de rodapé 3.

${ }^{10}$ Dos 13 diretores gerais da história do PMA, seis são estadunidenses. Além disso, a Diretoria Executiva do PMA está sob responsabilidade de um estadunidense de forma continuada desde 1992. Portanto, não é novidade histórica que um estadunidense seja nomeado para o principal cargo da agência (DIAS, 2016).
} 
no gráfico 3 (de acordo com os dados disponíveis). A ascendência da curva de 2018 para 2019 é bastante significativa, representando um crescimento em torno de 34\%. Em 2020, também há um aumento de $8 \%$ em relação a 2019. Os dados demonstram um resultado bastante expressivo diante de uma agenda de governo que, em tese, pretendia cortar gastos relacionados à assistência alimentar internacional oferecida pelos EUA.

Gráfico 3 - Contribuições dos EUA ao PMA ${ }^{11}$

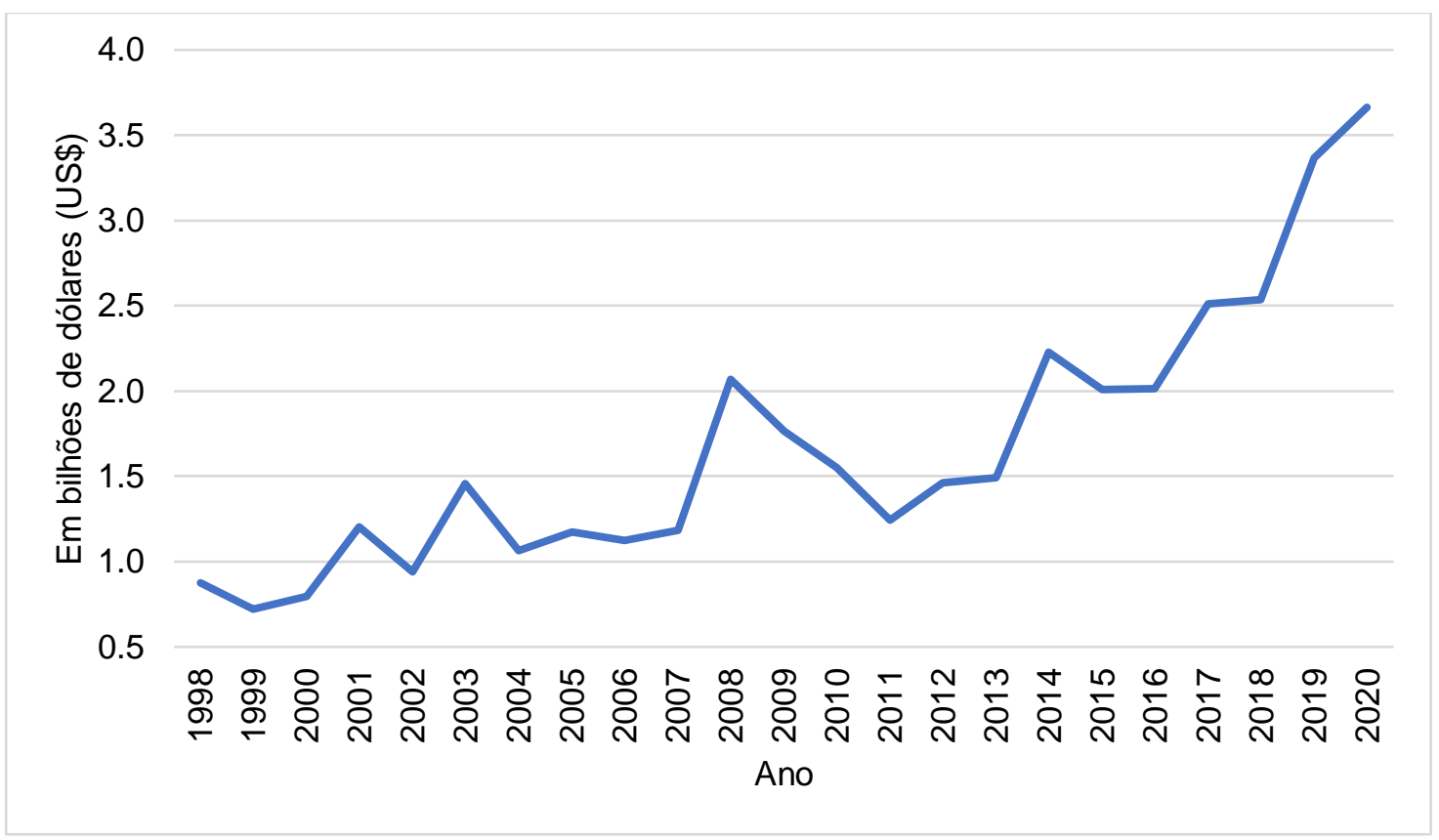

Fonte: Elaboração própria com base em WFP, 2021.

O terceiro fator a ser levado em consideração diz respeito à atuação do triângulo de ferro. Um triângulo de ferro refere-se ao estabelecimento de redes entre atores dos setores público e privado que interagem entre si para controlar uma determinada agenda política (DIVEN, 2006). De modo mais específico, o triângulo de ferro da assistência alimentar internacional nos EUA é formado por três principais grupos: o agronegócio; empresas de transporte marítimo; e ONGs de distribuição. É importante salientar que esse triângulo de ferro é principalmente favorável à modalidade de assistência alimentar baseada na entrega direta dos grãos produzidos e embalados nos EUA. Isso beneficia economicamente os

${ }^{11}$ Os valores em dólares no gráfico são nominais ou correntes, isto é, não estão corrigidos pela inflação. 
produtores e processadores agrícolas (responsáveis pelo fornecimento dos alimentos a serem doados); é favorável às empresas de transporte marítimo dos EUA, que formam um oligopólio e garantem contratos governamentais a preços significativos; e, por fim, é do interesse das ONGs de distribuição, que são contratadas pela USAID para administrar as doações e, portanto, conseguem financiar suas atividades (CLAPP, 2012; LIMA; DIAS, 2016).

Deve-se considerar também que várias dessas empresas envolvidas com a política de assistência alimentar internacional financiam campanhas políticas, o que em consequência favorece a criação e manutenção de uma rede na defesa da permanência da assistência alimentar de entrega direta de alimentos, o que abre espaço para uma prática intensiva de lobby a favor dos seus interesses (CLAPP, 2012). O triângulo de ferro, portanto, atua como uma força que limita o desengajamento internacional dos EUA, em geral, e a reforma dos instrumentos, em específico.

Na época em que o governo Trump apresentou a proposta para o ano fiscal de 2018, um dos grupos de lobistas ligado aos transportes marítimos, intitulado American Maritime Officers, criticou os cortes propostos no programa Food for Peace, mais especificamente no Título II, que autoriza a compra de mercadorias de origem nacional para doação direta ao estrangeiro. Cabe apontar que, por lei, 50\% das doações alimentares oriundas dos EUA devem ser feitas por navios de empresas estadunidenses sob a bandeira do país. Um corte profundo, ou até mesmo o fim de uma modalidade como o Food for Peace, representaria um prejuízo significativo para o oligopólio das empresas de transporte marítimo. Em um comunicado publicado logo após à apresentação da proposta orçamentária para o ano fiscal de 2018, a American Maritime Officers declarou que os cortes sugeridos (incluindo a modalidade Food for Peace) teriam um impacto devastador nas capacidades marítimas mercantes e de defesa nacional dos EUA. O documento deixou claro que o grupo em questão continuaria trabalhando no Capitólio (isto é, exercendo pressão nos congressistas) para garantir a autorização e o financiamento dos programas. A declaração ainda argumentava que o elemento mais prejudicial da proposta do orçamento era a completa eliminação do Título II do Food for Peace. O documento enfatizou também a decepção do grupo bem como o desejo de que o governo apoiasse de forma melhor os agricultores, fazendeiros e a comunidade marítima do país (AMO, 2017). 
Em 2018, quando o governo Trump apresentou uma proposta de orçamento para o ano fiscal de 2019 que incluía o fim do financiamento para programas de assistência alimentar (Food for Peace, McGovern-Dole Food For Education e Food for Progress), alguns grupos de interesse também apresentaram declarações em favor da continuidade desse tipo de ajuda externa. Um grupo lobista que apoia as exportações de trigo de nome The U.S. Wheat Associates, por exemplo, emitiu um documento intitulado "An Appeal to Protect International Food Assistance". No documento, o grupo afirmava que além de ajudar os necessitados em todo mundo, esses programas de assistência alimentar internacional trazem benefícios vitais para os cidadãos estadunidenses. Além disso, o grupo também argumentou que a assistência alimentar contribui para os esforços de segurança nacional (o mesmo discurso utilizado por congressistas estadunidenses que apoiam a continuidade desse tipo de ajuda externa). Mais do que isso, o grupo enfatizou a importância da utilização de commodities estadunidenses no lugar de doações em dinheiro, visto que "the use of U.S. commodities ties farmers directly to program beneficiaries". Por fim, o grupo pediu ao congresso que, como ocorrido para o orçamento de 2018, pudessem impedir a eliminação desses programas para o orçamento de 2019 (U.S. WHEAT ASSOCIATES, 2018).

As chamadas ONGs de distribuição também exerceram uma considerável pressão política para que os sucessivos cortes em assistência alimentar do governo Trump fossem desconsiderados. Em julho de 2019, no $65^{\circ}$ aniversário do Food for Peace, um grupo de instituições de caridade (dentre elas CARE, Action against Hunger, Catholic Relief Services, Save the Children) se reuniram no Capitólio com o intuito de defender a modalidade e, mais do que isso, requisitarem aos congressistas um aumento no financiamento aos programas de assistência alimentar internacional dos EUA. Esse grupo chegou a afirmar que os alimentos devem estar no topo da agenda de política externa (LAMBERS, 2019).

O triângulo de ferro da assistência alimentar internacional, portanto, parece ter sido elemento eficaz de resistência à mudança. Contudo, ele não é infalível e algumas reformas podem ocorrer. 
Em 2018, por exemplo, a Farm Bill12 autorizou que o Título II do Food for Peace fosse prorrogado por mais quatro anos (até 2023), mas fez algumas mudanças no programa. A principal delas foi a eliminação da obrigatoriedade de monetizar pelo menos $15 \%$ das commodities doadas através do Título II (MORGENSTERN, 2019). A monetização - uma prática realizada por ONGs responsáveis em implementar a assistência alimentar - é a venda dos produtos agrícolas doados pelos EUA nos mercados locais dos países receptores com a finalidade de financiar programas não emergenciais. A prática é criticada por especialistas por restringir o acesso das populações vulneráveis a mais comida, por prejudicar o mercado interno nos países receptores e por perder entre 20 a 25 centavos por dólar na venda dos produtos (CLAPP 2012; LIMA; DIAS, 2016). Com a mudança feita pela Farm Bill, a monetização só poderá ser realizada por meio de uma autorização legal (MORGENSTERN, 2019).

Por último, a disputa comercial entre EUA e China pode ter sido fator capaz de garantir a continuidade e aumento dos programas de assistência alimentar internacional estadunidense. No entanto, essa relação não pôde ser observada por falta de indícios corroborativos. É tratada aqui apenas como uma hipótese a ser estudada.

A guerra comercial entre China e EUA impactou as exportações agrícolas estadunidenses com destino a Pequim. A disputa teve início em março de 2018, quando o governo Trump impôs tarifas comerciais sobre importações chinesas num valor de US\$ 60 bilhões. A medida estava em conformidade com a política "America First" adotada pelo presidente Trump e que, nesse caso, mirava o déficit comercial estadunidense frente a demais países do globo em acordos bilaterais. Trump classificou a China como inimigo econômico e responsabilizou o país adversário pelas perdas de milhares de empregos, de bilhões de dólares em receitas e de roubar propriedade intelectual dos EUA (MENDONÇA et al, 2019).

Frente à retaliação dos Estados Unidos, a China impôs tarifas no valor de US\$ 34 bilhões sobre produtos estadunidenses, sendo a soja um dos mais atingidos (LANDLER; TANKERSLEY, 2018; ZHONG, 2018). Deu-se início a uma disputa comercial entre ambos os

\footnotetext{
${ }^{12} \mathrm{~A}$ Farm Bill é uma lei agrícola estadunidense, renovada a cada quatro anos, que trata dos programas da política agrícola do Departamento de Agricultura dos Estados Unidos (USDA), incluindo a assistência alimentar internacional.
} 
países que se estenderia por meses até um acordo firmado em dezembro de 2019 estabelecer uma trégua. Nesse mesmo mês, a China anunciou a revogação das tarifas impostas sobre os produtos agrícolas como uma demonstração de "boa vontade" (PATTON; CHEN, 2019).

A primeira fase do acordo que foi assinada entre ambos os países em janeiro de 2020 estabeleceu, dentre outras medidas, que a China compraria um adicional de US\$ 32 bilhões em produtos agrícolas dos EUA em dois anos (2020 e 2021), elevando a média anual de compras agrícolas para US\$ 40 bilhões (DONNAN; WINGROVE; MOHSIN, 2020).

Essa nova média anual é cerca de $60 \%$ maior do que a anterior à guerra comercial entre ambos os países, algo em torno de US\$ 25-30 bilhões. Durante a disputa, as perdas estadunidenses com exportações agrícolas para a China foram significativas, sobretudo para a soja. As tarifas impostas por Pequim à soja e demais produtos agrícolas foram inicialmente de $25 \%$ em julho de 2018 . Em setembro do mesmo ano, a tarifa sobre a soja chegou em $30 \%$ e até o final de 2019 alcançou 33\%. O impacto nas exportações agrícolas dos EUA para a China representou uma queda de $72 \%$, ficando em torno US\$ 7 bilhões de dólares anuais (FENG, 2020).

No caso específico da soja, como se observa no gráfico 4, há uma queda acentuada das exportações estadunidenses para a China. Enquanto que em 2017 a soja dos EUA representou 34,3\% do total das importações do grão na China, em 2018 esse índice caiu para 18,9\%, valor semelhante ao de 10 anos atrás. Em 2019, a importação de soja estadunidense se manteve semelhante ao ano anterior e em 2020 houve um aumento para $25,8 \%$, embora $8,5 \%$ abaixo do patamar anterior à disputa comercial. 
Gráfico 4 - Importações chinesas de soja

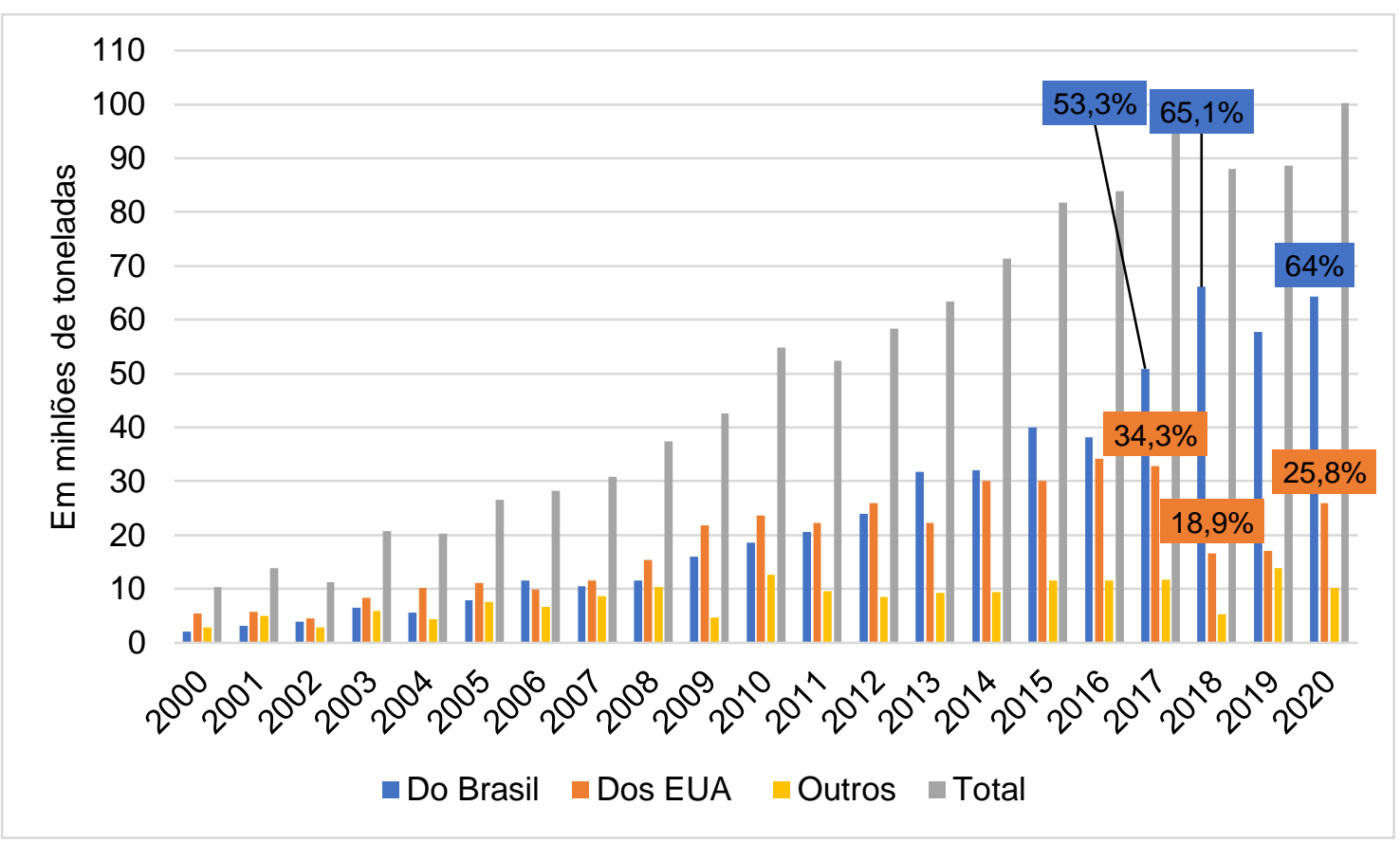

Fonte: Elaboração própria com base em UN, 2021.

A China, porém, não deixou de comprar soja. No mesmo gráfico se observa que as importações permaneceram e os EUA perderam mercado para o Brasil - maior produtor de soja do mundo - que elevou suas exportações da commodity para a China em 11,8\% de 2017 para 2018.

É fato que a produção nas fazendas estadunidenses representa apenas cerca de $1 \%$ do Produto Interno Bruto (PIB) dos EUA. Se considerarmos, no entanto, o setor agrícola e alimentar de um modo geral - levando em consideração campo e indústria - esse valor aumenta. Em 2017, ano anterior à disputa comercial, a participação foi de 5,4\% no PIB e a mão de obra empregada representou cerca de $11 \%$ do total de empregos nos EUA, e a soja é o produto agrícola mais valioso do país (USDA, 2017). Adicionalmente, a queda na demanda da soja dos EUA afeta a produção de outros importantes cultivos. Tendo em vista as tarifas impostas e uma esperada queda na demanda e no preço, grandes produtores agrícolas do centro-oeste do país decidiram cultivar milho ou trigo no lugar de soja, o que prejudicou os níveis de preços de ambas as commodities agrícolas. 
Em 2018, ano do início da disputa, o Departamento de Agricultura dos Estados Unidos (USDA, sigla em inglês) aprovou um plano emergencial de US\$ 12 bilhões para a agricultura com o objetivo de compensar os preços baixos e a queda de demanda (PATTON; CHEN, 2019). O setor era politicamente estratégico para Trump, pois apoiou amplamente sua eleição.

Tendo em vista o cenário acirrado da disputa, em maio de 2019 Trump propôs um segundo plano de ajuda emergencial ao setor agrícola (que seria apresentado em julho do mesmo ano no valor de US\$ 16 bilhões em subsídios) (RAPPEPORT, 2019). No mesmo mês, o presidente também indicou escoar excedentes agrícolas na forma de assistência alimentar internacional. Em seu perfil oficial na rede social Twitter, Trump publicou:

With the over 100 Billion Dollars in Tariffs that we take in, we will buy.........agricultural products from our Great Farmers, in larger amounts than China ever did, and ship it to poor \& starving countries in the form of humanitarian assistance. In the meantime we will continue to negotiate with China in the hopes that they do not again try to redo deal! (TRUMP, 2019).

Donald Trump erroneamente afirmou na mesma rede social que a compra seria realizada com as tarifas pagas pela China (TRUMP, 2019). Na verdade, são as importadoras empresas estadunidenses ou estrangeiras registradas no país - quem arcam com os custos das tarifas. O Estado, na verdade, é remunerado com o pagamento do imposto sobre as importações.

Além disso, existem outros dois fatores que dificultariam a solução proposta por Trump. Em primeiro lugar, qualquer fundo financeiro desse tipo faz parte do Tesouro dos EUA e é do Congresso a competência de gerir os gastos do país. Ou seja, não é nada simples arrecadar dinheiro e gastá-lo ao sabor do Executivo. E em segundo lugar, a soja e o milho commodities mais prejudicadas na disputa comercial - são mais utilizadas como ração animal e insumo industrial do que como alimento, o que inviabilizaria um fornecimento massivo na forma de assistência alimentar internacional (PATTON; CHEN, 2019; DURISIN, 2019).

Analisando os dados da USAID sobre assistência alimentar internacional percebe-se que não há um aumento significativo de gastos com o Título II do Food for Peace, que prevê a doação direta de produtos agrícolas na forma de assistência alimentar emergencial para países em desenvolvimento e entidades privadas. O que se percebe, entre 2018 e 2019 é uma 
leve baixa, cerca de 4,7\% (USAID, 2021). Mais do que isso, não há uma maior participação de produtos agrícolas derivados de milho e soja - os mais afetados pela disputa comercial - em relação aos demais (como trigo e sorgo, por exemplo) (USAID, 2018; 2019).

No entanto, pode-se pensar que a disputa comercial entre EUA e China despertou o governo Trump para a importância estratégica da política de assistência alimentar internacional na produção agrícola estadunidense. Isso ficou claro quando o presidente propôs utilizar a produção agrícola para doações internacionais a países famintos - mesmo sendo esse tipo de doação altamente controverso (PORTILLO, 1987; CLAPP, 2012, LIMA; DIAS, 2016).

\section{CONSIDERAÇÕES FINAIS}

A política externa do governo Trump preconizava a diminuição do engajamento internacional dos EUA por meio da ajuda externa. No entanto, os dados relacionados às doações alimentares feitas pelo país durante a gestão Trump apontaram para uma continuidade e, no caso do PMA, um aumento considerável da assistência alimentar internacional.

Se, por um lado, Trump não logrou desmaterializar o engajamento de Washington nesse campo, parece que o governo Trump conseguiu influenciar em parte a direção da ajuda estrangeira a partir da sua política externa baseada no custo-benefício, principalmente no que se refere aos países considerados "bons" ou "maus" para os interesses estadunidenses.

Em nossa compreensão, a continuidade e aumento da ação multilateral e de assistência alimentar internacional de Trump em meio a uma política externa que se guia pelo unilateralismo responde no mínimo a três fatores: (a) a posição contrária de congressistas e membros do próprio governo com relação aos cortes em ajuda externa propostos pelos "falcões do orçamento" do governo Trump; (b) a escolha estratégica do republicano David Beasley como diretor geral do Programa Mundial de Alimentos; e o (c) lobby feito pelo triângulo de ferro (produtores e processadores agrícolas, empresas de transporte marítimo e ONGs de distribuição), grupo diretamente interessado pela continuidade dos gastos do 
Não está claro se houve maior participação de produtos agrícolas atingidos pela guerra comercial nas doações internacionais. Contudo, essa parece uma hipótese plausível e importante de ser investigada, pois, em sendo confirmada, mais uma vez os Estados Unidos estariam recorrendo à assistência alimentar internacional como uma forma de resolver seus problemas de mercado. Embora isso pareça uma boa ideia para os que sofrem com a fome, os especialistas no campo demonstraram como isso é problemático, tanto em termos de dumping comercial, quanto no seu potencial de desorganizar a produção dos países que recebem os produtos gratuitamente ou abaixo do valor de mercado. Ao mesmo tempo, devemos sempre recordar que esses foram os anos em que houve o maior número de refugiados e pessoas deslocadas já registrado na História e, portanto, não se pode descartar que o contexto humanitário internacional tenha demandado - com as mediações dos atores domésticos e do diretor geral do PMA - maior engajamento dos Estados Unidos. O que aparenta ser menos duvidoso é que a gestão Trump parece ter percebido que a política de assistência alimentar internacional dos EUA pode ser uma ferramenta útil na agenda America First.

Em suma, a dificuldade que o governo vivenciou em pôr fim aos programas de assistência alimentar internacional mostrou o enraizamento desse tipo de política em estruturas institucionais e em grupos de interesses articulados na sociedade. 0 estudo desse caso, certamente pequeno no conjunto da política externa estadunidense, aponta que a autonomia do chefe do Executivo em determinar a ação internacional dos Estados Unidos pode encontrar limites internos, sugerindo que uma guinada completa de Washington, no sentido de desfazer a ordem internacional calcada (ainda que manca) no multilateralismo, pode encontrar resistências significativas na própria Casa Branca, no Capitólio e na sociedade estadunidense.

\section{REFERÊNCIAS}

AMO (American Maritime Officers). Administration seeks to eliminate Food for Peace Title II, roll back MSP funding in FY 2018 budget. 2017. Disponível em:< http://www.amo-union.org/News.aspx?code=201706-02> Acessado em: 28 fev. 2020. 
BOYER, Dave. Nancy Pelosi calls Donald Trump foreign aid cuts illegal. Washington Times, 2019. Disponível em:< https://www.washingtontimes.com/news/2019/aug/18/nancy-pelosicalls-donald-trump-foreign-aid-cuts-i/>. Acessado em: 05 jul. 2021.

CASEY, Alyssa R.; MORGENSTERN, Emily M. International Food Assistance: FY2020 Appropriations. Congressional Research Service. 2020. Disponível em: <https://www.everycrsreport.com/files/20200304 R46255 088b7172f6fa199e02d6cf58 b5396d22ea3034d0.pdf> Acessado em: 01 mai. 2020.

CLAPP, Jenifer. Hunger in the Balance: the new politics of international food aid. Londres: Cornell University Press, 2012.

DIAS, Atos. 0 impacto da política de ajuda alimentar internacional dos Estados Unidos na cooperação multilateral do Programa Mundial de Alimentos. Trabalho de Conclusão de Curso, Universidade Federal da Paraíba, 2016.

DIVEN, Polly. A Coincidence of Interests: the hyperpluralism of U.S. Food Aid Policy. Foreign Policy Analysis, v. 2, n. 4, p. 361-384, 2006.

DONNAN, Shawn; WINGROVE, Josh; MOHSIN, Saleha. U.S. and China Sign Phase One of Trade Deal. Bloomberg, 2020. Disponível em:<https://www.bloomberg.com/news/articles/2020-01-15/u-s-china-sign-phase-one-oftrade-deal-trump-calls-remarkable> Acessado em: 28 abr. 2020.

DURISIN, Megan. President Trump Says U.S. Will Buy American Farmers' Crops to Offset China Trade Losses. Time, 2019. Disponível em:<https://time.com/5587231/trump-us-cropschina-trade-war/> Acessado em: 28 abr. 2020.

EISENHOWER, Dwight D. Statement by the President Upon Signing Bill Amending the Agricultural Trade Development and Assistance Act. The American Presidency Project. 1955. Disponível em: $<$ https://www.presidency.ucsb.edu/documents/statement-the-presidentupon-signing-bill-amending-the-agricultural-trade-development-and>. Acessado em: 05 jul. 2020.

FENG, Zhaoyin. EUA e China assinam acordo após 2 anos de guerra comercial: o que mudou ao longo da disputa? BBC, 2020. Disponível em:<https://www.bbc.com/portuguese/internacional-51119805> Acessado em: 27 abr. 2020.

FRANCIS, Samuel. The Paleo Persuasion. The American Conservative. 2002. Disponível em: $<$ https://www.theamericanconservative.com/articles/the-paleo-persuasion/> Acessado em: 23 abr. 2020.

FUKUYAMA, Francis. O fim da história e o último homem. São Paulo: Rocco, 1992. 
LAMBERS, William. Six-five years later, Ike's Food for Peace is our best hope. TCPALM, 2019. Disponível em:< https://www.tcpalm.com/story/opinion/contributors/2019/07/08/sixtyfive-years-later-ikes-food-peace-our-best-hope/1655323001/> Acessado em: 20 jan. 2020.

LANDLER, Mark; TANKERSLEY, Jim. Trump Hits China with Stiff Trade Measures. New York Times, 2018. Disponível em:<https://www.nytimes.com/2018/03/22/us/politics/trump-willhit-china-with-trade-measures-as-white-house-exempts-allies-from-tariffs.html $>$ Acessado em: 26 abr. 2020.

LEIMBACH, Dulcie. Cowboys may be running the World Food Program, but Donations Keep Coming. PassBlue, 2019. Disponível em:< https://www.passblue.com/2019/10/27/cowboysmay-be-running-the-world-food-program-but-donations-keep-coming/> Acessado em: 01 dez. 2019.

LIMA, Thiago; DIAS, Atos. Ajuda alimentar internacional dos EUA: política externa, interesses econômicos e assistência humanitária. Revista Brasileira de Políticas Públicas e Internacionais, v. 1, n. 1, p. 189-211, 2016.

LYNCH, Colum. U.N to put Trump Appointee at Head of World Food Programme to help stave off U.S. cuts. Foreign Policy, 2017. Disponível em:<https://foreignpolicy.com/2017/03/24/u-n-to-put-trump-appointee-at-head-of-worldfood-program-to-help-stave-off-cuts/> Acessado em: 02 jan. 2020.

MARIANO, Karina L. P.; MATTOS, Angelo R.; SUGAHARA, Daniela R. Do NAFTA ao USMCA: Trump e os interesses nacionais. Perspectivas, v. 54, p. 235-260, jul./dez. 2019.

MENDONÇA, Filipe; THOMAZ, Lais Forti; LIMA, Thiago; VIGEVANI, Tullo. "AMERICA FIRST BUT NOT ALONE": uma (nem tão) nova política comercial dos Estados Unidos com Donald Trump. Revista Tempo Do Mundo, vol. 5, n. 1, p. 107-141, 2019.

MENEZES, Henrique Z., CARVALHO, Pedro H. M., LEITE, Alexandre C. C. Will Trump make China great again? A saída dos Estados Unidos do TPP e as respostas chinesas. In BOJIKIAN, Neusa M., MENEZES, Henrique Z. A economia política do governo Trump. Curitiba: Appris, 2021.

MILNER, Helen V. Interest, institutions and information. Domestic politics and international relations. Princeton: Princeton University Press, 1997.

MORELLO, Carol. State Department's 28 percent cut hit foreign aid, U.N. and climate change. Washington Post, 2017. Disponível em:<

https://www.washingtonpost.com/world/national-security/state-departments-28-percentcuts-hit-foreign-aid-un-and-climate-change/2017/03/15/294d7ab8-0996-11e7-a15fa58d4a988474 story.html> Acessado em: 12 jan. 2020. 
MORGENSTERN, Emily M. International Food Assistance: Food for Peace Nonemergency Programs. Congressional Research Service. 2019. Disponível em:<https://fas.org/sgp/crs/row/R45879.pdf> Acessado em: 01 mai. 2020.

PATTON, Dominique; CHEN, Yawen. China to waive tariffs on some U.S. soybeans, pork in goodwill gesture. Reuters, 2019. Disponível em:<https://www.reuters.com/article/us-usatrade-china-tariffs/china-to-waive-tariffs-on-some-u-s-soybeans-pork-idUSKBN1YAOFW> Acessado em: 27 abr. 2020.

PECEQUILO, Cristina S. Os Estados Unidos de H. Bush a Donald J. Trump (1989/2017):

Dinâmicas políticas de consenso e polarização. Revista Esboços v. 24, n. 38, p. 339-359, 2017.

POGGIO, Carlos Gustavo. Qual conservadorismo? Da América de Trump ao Brasil de Bolsonaro. 2018. Disponível em:<https://estadodaarte.estadao.com.br/conservadorismosda-america-de-trump-ao-brasil-de-bolsonaro/> Acessado em: 12 dez. 2019.

PORTILLO, Luis. ¿Alimentos para la Paz? La “ayuda" de Estados Unidos. Madrid: lepala Editorial, 1987.

QUINN, B. Will Trump honour pledge to stop sending aid to countries that hate us? The Guardian, 2016. Disponível em:<

https://www.theguardian.com/global-development/2016/nov/13/will-trump-presidencyhonour-pledge-stop-sending-foreign-aid-to-countries-that-hate-us-usaid> Acessado em: 25 jan. 2020.

RAPPEPORT, Alan. U.S. Rolls Out More Farm Aid as Soy Growers Urge Trade Cease-Fire. New York Times, 2019. Disponível em:<https://www.nytimes.com/2019/07/25/us/politics/farmaid-trade-wars.html> Acessado em: 28 abr. 2020.

STOKES, Doug. Trump, American hegemony and the future of the liberal international order. International Affairs, v. 94, n. 1, p. 133-150, 2018.

TRUMP, Donald J. Talks with China continue in a very congenial manner... 2019. Twitter: @realDonaldTrump. Disponível em:<https://twitter.com/realDonaldTrump/status/1126815126584266753> Acessado em: 28 abr. 2020.

UNITED NATIONS (UN). UN Comtrade Database. 2021. Disponível em:<https://comtrade.un.org/data/> Acessado em: 23 jun. 2021.

U.S. WHEAT ASSOCIATES. An Appeal to Protect International Food Assistance. 2018.

Disponível em:< https://www.uswheat.org/wheatletter/an-appeal-to-protect-internationalfood-assistance/> Acessado em: 28 jan. 2020.

USA SENATE. State, Foreign Operations, and Related Programs. 2019. Disponível em:< 
https://www.appropriations.senate.gov/subcommittees/state-foreign-operations-andrelated-programs> Acessado em: 29 jan. 2020.

USAID (United States Agency for International Development). USAID Data Services. 2021. Disponível em:<https://explorer.usaid.gov/> Acessado em: 10 jun. 2021.

USAID (United States Agency for International Development). U.S. Agency for International Development International Food Assistance Report: Fiscal Year 2018. 2019. Disponível em:<https://www.usaid.gov/sites/default/files/documents/1869/USAIDInternationalFood A ssistanceReportFY2018.pdf> Acessado em: 29 abr. 2020.

USAID (United States Agency for International Development). U.S. International Food Assistance Report: Fiscal Year 2017. 2018. Disponível em:<https://www.usaid.gov/sites/default/files/documents/1867/FY 2017 IFAR.pdf> Acessado em: 29 abr. 2020.

USDA (United States Department of Agriculture). Ag and Foods Sectors and the Economy. 2017. Disponível em:<https://www.ers.usda.gov/data-products/ag-and-food-statisticscharting-the-essentials/ag-and-food-sectors-and-the-economy/> Acessado em: 28 abr. 2020.

VIGEVANI, Tullo. MENDONÇA, Filipe, LIMA, Thiago. Poder e Comércio: a política comercial dos Estados Unidos. São Paulo: Editora Unesp, 2018.

WADHAMS, Nick; FABIAN, Jordan. Trump to scale back planned foreign aid cuts after pompeo plea. Bloomberg, 2019. Disponível

em: $<$ https://www.bloomberg.com/news/articles/2019-08-20/trump-to-scale-back-plannedforeign-aid-cuts-after-pompeo-plea> Acessado em: 10 jan. 2020.

WERFT, Meghan. The Trumps administration wants to cut food aid amid a famine - but congress can stop it. Global Citizen, 2017. Disponível em:<

https://www.globalcitizen.org/en/content/congress-listens-to-the-case-for-keeping-us-fooda/> Acessado em: 15 dez. 2019.

WFP (World Food Programme). Contributions by Year. 2021. Disponível em:<https://www.wfp.org/funding> Acessado em: 23 jun. 2021.

WHITE HOUSE. National Security Strategy. 2017. Disponível em:<https://www.whitehouse.gov/wp-content/uploads/2017/12/NSS-Final-12-18-20170905.pdf> Acessado em: 30 abr. 2020.

WOLTERMANN, Chris. What is Paleoconservatism? Telos, n. 97, p. 9-20, 1993.

WONG, Edward; KARNI, Annie; COCHRANE, Emily. Trump Administration Drops Proposal to Cut Foreign Aid After Intense Debate. New York Times, 2019. Disponível 
em:<https://www.nytimes.com/2019/08/22/us/politics/trump-foreign-aid.html> Acessado em: 12 dez. 2019.

ZHONG, Raymond. China Strikes Back at Trump's Tariffs, but Its Consumers Worry. New York Times, 2018. Disponível em:<https://www.nytimes.com/2018/07/06/business/china-trumptrade-war-tariffs.html> Acessado em: 26 abr. 2020. 